\title{
Cocaine Self-Administration Alters the Morphology of Dendrites and Dendritic Spines in the Nucleus Accumbens and Neocortex
}

\author{
TERRY E. ROBINSON, ${ }^{1 *}$ GRAZYNA GORNY, ${ }^{2}$ ELIZABETH MITTON, ${ }^{1}$ AND BRYAN KOLB ${ }^{2}$ \\ ${ }^{1}$ Department of Psychology and Neuroscience Program, The University of Michigan, Ann Arbor, Michigan, USA \\ ${ }^{2}$ Department of Psychology and Neuroscience, University of Lethbridge, Lethbridge, Alberta, Canada
}

\begin{abstract}
KEY WORDS Prefrontal cortex; Golgi; neuronal morphology; sensitization; plasticity
ABSTRACT We studied the influence of cocaine use on the structure of neurons in brain regions that contribute to its rewarding effects by allowing rats to self-administer cocaine $(0.33 \mathrm{mg} /$ infusion) for $1 \mathrm{~h}$ a day for 1 month. Control animals were left undisturbed or allowed to work for food for the same period of time. After an additional 1 month drug-free period the brains were processed for Golgi-Cox staining. In rats that self-administered cocaine, but not rats that worked for food, there was a significant increase in dendritic branching and in the density of dendritic spines on medium spiny neurons in the shell of the nucleus accumbens and on pyramidal cells in the prefrontal and parietal (but not occipital) cortex. There was also a 2.6 -fold increase in the incidence of spines with multiple heads (branched spines) on medium spiny neurons. Finally, in the prefrontal cortex some of the apical dendrites of pyramidal cells appeared misshaped, having large bulbous structures on their terminal tips. We speculate that cocaine self-administration experience alters patterns of synaptic connectivity within limbocortical circuitry that is thought to contribute to cocaine's incentive motivational effects and may have neuropathological effects in frontal areas involved in decision making and judgment. Together, these two classes of drug-induced neuroadaptations may contribute to the development of addiction. Synapse 39:257-266, 2001.
\end{abstract}

(๑) 2001 Wiley-Liss, Inc.

\section{INTRODUCTION}

Repeated exposure to psychostimulant drugs results in the development of tolerance, sensitization, dependence, and, eventually, addiction (Edwards 1981; Jaffe 1992), all of which are thought to be due at least in part to drug-induced changes in the organization of the nervous system (Koob and Bloom, 1988; Nestler et al., 1993; Robinson and Berridge, 1993; White and Kalivas, 1998). For example, repeated intermittent treatment with amphetamine or cocaine produces a progressive and very long-lasting increase in their psychomotor activating and incentive motivational effects, a phenomenon referred to as behavioral sensitization (Segal et al., 1981; Robinson and Becker, 1986; Schenk and Partridge, 1997). Behavioral sensitization has been associated with persistent biochemical adaptations in mesostriatal, mesolimbocortical, and corticostriatal circuitry (Kalivas and Stewart, 1991; Robinson and Berridge, 1993; White and Kalivas, 1998), including alterations in dopamine (Robinson and Becker, 1986), serotonin (Parsons and Justice, 1993), norepinephrine
(Camp et al., 1997), and acetylcholine neurotransmission (Bickerdike and Abercrombie, 1997). Furthermore, there is rapidly accumulating evidence that excitatory amino acid neurotransmission also plays a critical role in sensitization processes (Karler et al., 1989; Clark and Overton, 1998; Wolf, 1998).

The fact that there are so many drug-induced adaptations in so many mesotelencephalic and corticostriatal neurotransmitter systems, and that they can be so long-lasting, suggests that psychomotor stimulant drugs induce fundamental alterations in the organization of these neural circuits, including alterations in patterns of synaptic connectivity (Pierce and Kalivas, 1997). Consistent with this notion, we recently reported that repeated intermittent treatment with am-

Contract grant sponsors: the National Institute on Drug Abuse (USA) and the National Science and Engineering Research Council of Canada.

*Correspondence to: Dr. Terry E. Robinson, Department of Psychology, Biopsychology Program, The University of Michigan, 525 E. University (East Hall), Ann Arbor, MI 48109, USA. E-mail: ter@umich.edu

Received 7 May 2000; Accepted 11 July 2000 
phetamine, cocaine, or morphine produces changes in the organization of dendrites and the density of dendritic spines on medium spiny neurons in the nucleus accumbens and pyramidal cells in the prefrontal cortex (Robinson and Kolb, 1997, 1999a,b). This is important because dendritic spines are known to be the major locus of excitatory signaling in the brain, and also the primary site whereby experience can alter synaptic efficacy (Horner, 1993; Harris and Kater, 1994; Shepherd, 1996).

In our previous studies, however, drugs were administered by the experimenter; drug administration was not contingent on an animal's behavior. This is potentially a critical consideration because the neurobiological consequences of drug administration can vary as a function of whether a drug is administered contingent on an animal performing a specific action (e.g., pressing a lever in a self-administration experiment) or noncontingently, independent of its actions (Smith and Dworkin, 1990; Wilson et al., 1994; Dworkin et al., 1995a,b; Mark et al., 1999). It is not known, therefore, whether drug self-administration alters the morphology of dendrites in mesolimbocortical circuitry thought to be critical in mediating drug reward. Drug self-administration procedures are widely accepted as the best available for modeling human drug-taking behavior (Katz, 1990; Markou et al., 1993), so it is critical to determine whether drug self-administration experience alters neuronal morphology in the nucleus accumbens and/or prefrontal cortex in a similar manner to that seen with experimenter-administered drug (Robinson and Kolb, 1997, 1999a). If it does not, it is unlikely the drug-induced alterations in neuronal morphology described previously (Robinson and Kolb, 1997, 1999a) are relevant to addiction. The goal of the present experiment, therefore, was to characterize the effects of cocaine self-administration on the structure of dendrites and dendritic spines in the nucleus accumbens and neocortex, including the prefrontal cortex.

\section{MATERIALS AND METHODS}

Male Sprague-Dawley rats purchased from Harlan (Indianapolis, IN), 200-225 g upon arrival, were used. After a week to acclimatize to the animal colony all rats were deprived of $85-90 \%$ of their normal weight by restricting access to food to the period following test sessions, when they received their daily rations. All animals were maintained on this feeding schedule until the end of the self-administration phase of the experiment. After 3 days of food deprivation all rats (except control animals; see below) were placed in an operant chamber (Med Associates) where they were allowed to bar-press on an FR1 schedule for a $45 \mathrm{mg}$ Noyes ${ }^{\circledR}$ food pellet. Each chamber had two levers and responses on both levers were recorded, but only one had programmed consequences. Test sessions lasted for $1 \mathrm{~h}$ each day until the animals showed stable levels of responding, which took about 5 days.

\section{Surgical procedures}

After this, animals that were to later receive cocaine were anesthetized with sodium pentobarbital $(50 \mathrm{mg} /$ $\mathrm{kg}$ ) and a chronic indwelling catheter was placed into the right external jugular vein using procedures described previously (Weeks, 1972; Crombag et al., 1996; Browman et al., 1998). The external end of this catheter was passed subcutaneously to an infusion port mounted between the shoulder blades, similar in design to that described by Caine et al. (1993). For 2 days postoperatively the catheter was filled each day with gentamicin $(50 \mathrm{mg} / \mathrm{ml})$, of which $50 \mu \mathrm{l}$ was given i.v. During the course of the experiment the catheters were flushed once a day with approximately $0.15 \mathrm{ml}$ of a sterile heparin-saline solution (30 USP units $/ \mathrm{ml}$ ) to help maintain catheter patency. Two days after surgery, and once a week throughout the experiment (late on Fridays), catheter patency was determined by giving an i.v. infusion of $0.1 \mathrm{ml}$ of $50 \mathrm{mg} / \mathrm{ml}$ thiopental sodium (Pentothal ${ }^{\circledR}$ ). The catheter was considered patent if the animal became limp within $3 \mathrm{sec}$. Animals in the other groups received only sham surgery, consisting of anesthesia, an incision, and isolation of the external jugular vein (which was not punctured).

\section{Groups and testing procedures}

Approximately 5 days after surgery the animals were again allowed to bar-press for food for 1-2 days. At this point the animals were divided into one of three groups. One group (Control) consisted of six animals that had not undergone operant pretraining. For the remainder of the self-administration phase of the experiment these animals were maintained on the restricted feeding schedule and were weighed each day. A second group (Cocaine) was trained to self-administer cocaine ( $\mathrm{n}=8$; see below) and a third group (Food; $\mathrm{n}=$ 6 ) was allowed to continue working for food on each test session, as in the pretraining phase.

Each self-administration session began by placing a rat into an operant chamber, attaching its catheter to the liquid swivel, and presenting one priming infusion of cocaine. Cocaine $(0.33 \mathrm{mg} /$ infusion $)$ was delivered in $100 \mu \mathrm{l}$ of phosphate-buffered $0.09 \%$ saline over $5.5 \mathrm{sec}$. A cue light above the active lever signaled the availability of cocaine and after the initial priming infusion each response on the active lever resulted in the delivery of cocaine (FR1). At the same time the light above the active lever was turned off, the houselights and white noise were turned on, and for the duration of this 20 -sec timeout period further responses had no consequences. After the timeout period the next trial commenced. The initial test sessions were $2 \mathrm{~h}$ in duration, but after the animals acquired stable cocaine self-ad- 


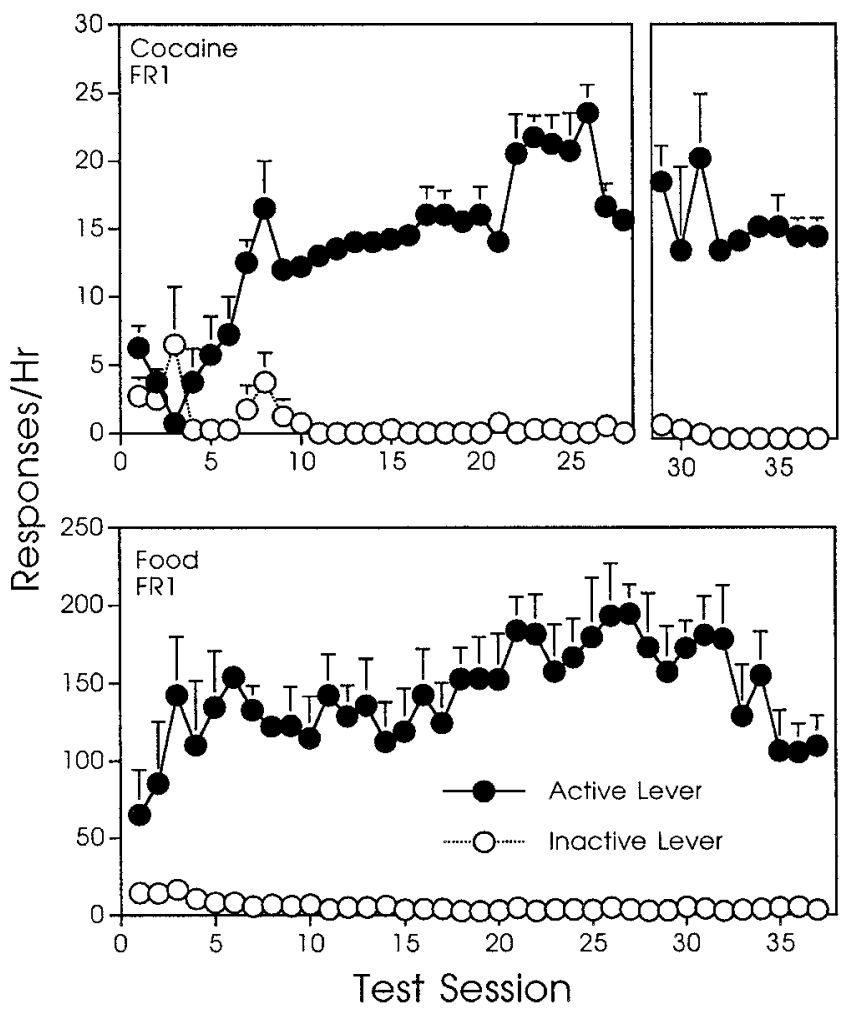

Fig. 1. Mean ( \pm SEM) lever presses (responses/h) on the active lever (solid circles) and the inactive lever (open circles) in rats working on an FR1 schedule for $0.33 \mathrm{mg} /$ infusion of cocaine (top) or food (bottom) across test sessions. In the cocaine group one rat lost its catheter after day 28, which is the reason for the break in the graph. For animals working for food the first test session shown is the first session after surgery (see Materials and Methods).

ministration behavior, which took about 7 days (see Fig. 1), the remaining sessions were only $1 \mathrm{~h}$ long. Test sessions were held each weekday but not on weekends. This procedure continued for approximately 7 weeks (37 test sessions). In the Cocaine group three rats were tested for the entire 37 sessions, but one rat was tested for only 28 sessions before its catheter broke. The remaining rats in this group were eliminated from the experiment because of technical difficulties or because they became ill. All animals in the Food group were tested for 37 test sessions. After their last test session all animals were left undisturbed in their home cages for 30 days, during which time they had unlimited access to food.

\section{Anatomical procedures}

After this 30-day drug-free period all the animals were given an overdose of sodium pentobarbital and then were perfused through the heart with $0.9 \%$ saline. There were no group differences in body weight at the time of sacrifice (Controls, $420 \pm 7.2 \mathrm{~g}$; Food, $421 \pm 3.4$; Cocaine, $431 \pm 6.2$ ). The brains were processed for Golgi-Cox staining using exactly the same procedures described previously (Robinson and Kolb, 1997; Gibb and Kolb, 1998). Cells in four brain regions were selected for analysis: medium spiny neurons in the shell of the nucleus accumbens, Layer $\mathrm{V}$ pyramidal neurons in the prefrontal cortex (specifically area Cg3 according to Zille's (1985) terminology), Layer III pyramidal cells in the parietal cortex (Par1, primary somatosensory cortex), and Layer III pyramidal cells in the occipital cortex (Oc1, primary visual cortex). All slides were coded so that the person responsible for cell selection and drawing (G.G.) was blind to the experimental condition. Four measures of dendritic structure were obtained from camera lucida drawings. First, dendritic length was estimated by placing an overlay of concentric rings over the drawing of each cell and counting the number of ring intersections made by each dendrite, as described Sholl (1981). Second, the total number of dendritic branches (indicated by bifurcations) was counted at each order away from the cell body or dendritic shaft, as described by Coleman and Riesen (1968). Third, spine density was determined by tracing at least a $10 \mu \mathrm{m}$ length of dendrite (at $1000 \times$ ), calculating its exact length, counting all the spines visible along the length of dendrite and then expressing spine density as the total number of spines $/ 10 \mu \mathrm{m}$. Fourth, the number of branched spines (spines with multiple heads) along a given length of dendrite was counted at $2000 \times$. These measures were obtained from five cells in each hemisphere, which were then averaged, as described by Robinson and Kolb (1997, 1999a). Group differences for each measure in each structure were determined by conducting one-way ANOVA followed by Fisher's PLSD tests when appropriate, using hemisphere as the unit of analysis.

\section{RESULTS \\ Behavior}

Figure 1 illustrates cocaine (top) and food (bottom) self-administration performance across test sessions. After acquisition, animals given access to cocaine took approximately 15-20 infusions per hour, which given the weight of the animals at the time of testing was equal to about $15-20 \mathrm{mg} / \mathrm{kg} / \mathrm{h}$. Figure 1 (bottom) illustrates that animals given access to food showed a much higher operant rate than those working for cocaine, making about 125-175 responses on the active lever per hour.

\section{Anatomy: nucleus accumbens}

Prior cocaine self-administration significantly altered the structure of dendrites on medium spiny neurons in the shell of the nucleus (Fig. 2A-C). There was a significant effect of treatment on the number of dendritic branches (Fig. 2A; F = 4.96, $P=0.015$ ), on dendritic length as indicated by the number of ring intersections using a Sholl (1981) analysis (Fig. 2B; $\mathrm{F}=6.63, P=0.005)$, and on spine density (Fig. $2 \mathrm{C} ; \mathrm{F}=$ 


\section{Branches Sholl Spines}
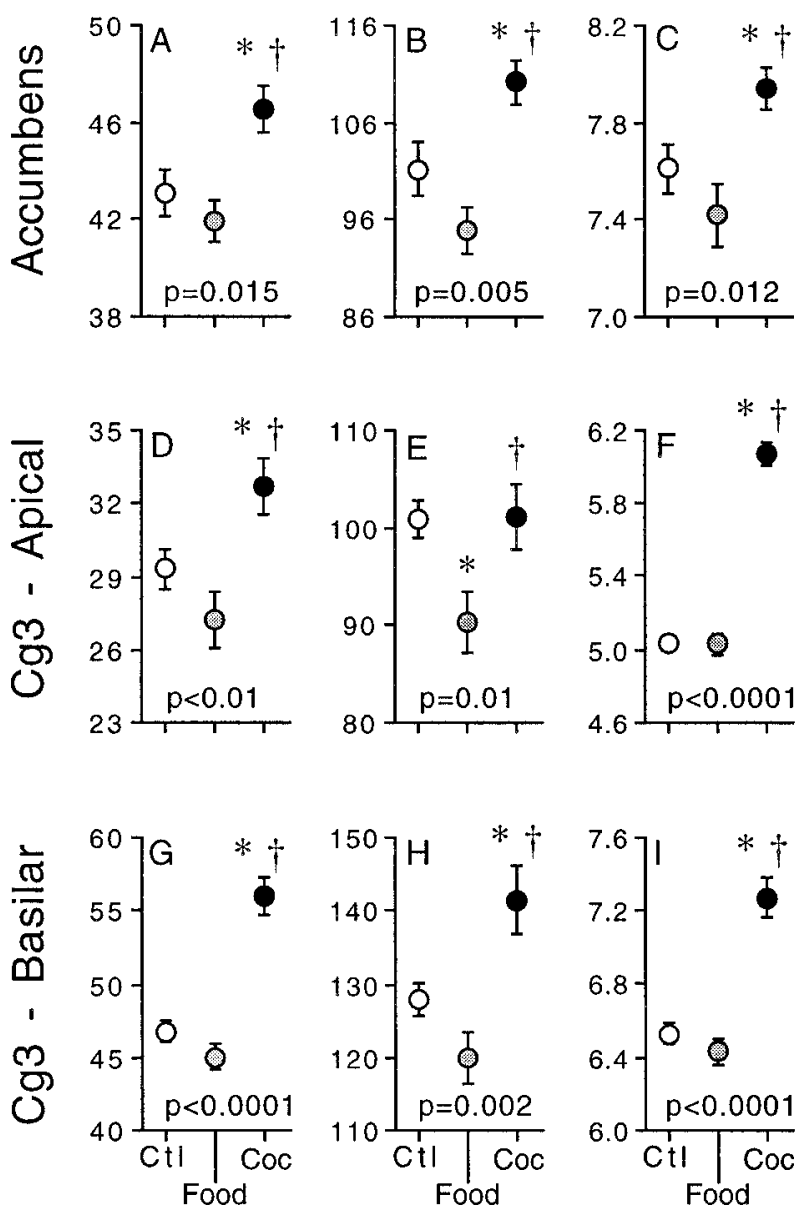

Fig. 2. Mean ( \pm SEM) number of dendritic branches (left panels), ring intersections based on a Sholl analysis (center panels), and dendritic spines (spines $/ 10 \mu \mathrm{m}$; right panels) on medium spiny neurons in the shell of the nucleus accumbens (top), apical dendrites of pyramidal cells in the prefrontal cortex (Cg3-Apical), and basilar dendrites of $\mathrm{Cg} 3$ pyramidal cells, in control rats (Ctl) and rats that had bar-pressed for either food or cocaine (Coc). The animals had been left undisturbed for 30 days since the last test session before their brains were obtained. $P$-values for one-ways ANOVAs are given in each panel. Asterisks $(*)$ indicate groups that differed significantly from the control group and daggers $(\dagger)$ groups that differed from the food group.

$5.25, P=0.012$ ). Relative to the control group, animals that self-administered cocaine showed an $8.1 \%$ increase in dendritic branching, an $8.9 \%$ increase in ring intersections and a $4.3 \%$ increase in spine density (Fisher's tests, $P<0.05$ ). Animals that worked for food differed from the cocaine group on all measures, but did not differ from the control group on any measure (Fig. 2).

Figure 3 show the results of a second analysis of spines on the terminal tips of dendrites of accumbens medium spiny neurons (at $2000 \times$ rather than $1000 \times$ ) to determine the effect of cocaine self-administration on the incidence of branched spines, that is, spines with multiple heads (Comery et al., 1996; Sorra et al., 1998).

\section{Nucleus Accumbens}

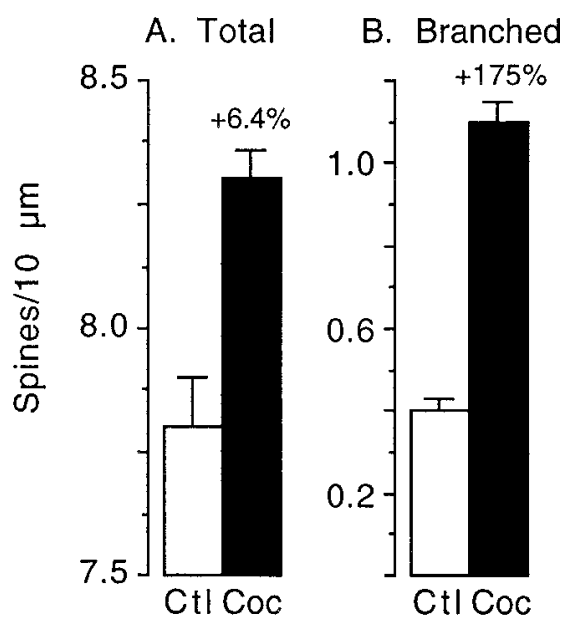

Fig. 3. Mean ( \pm SEM) total number of spines $(\mathbf{A})$ and of branched spines (B) on the terminal tips of medium spiny neurons in the shell of the nucleus accumbens in control animals (Ctl) and animals that self-administered cocaine (Coc) in the past. The groups differed significantly (see text).

In this second analysis animals that self-administered cocaine showed a $6.4 \%$ increase in total spine density, relative to the control group ( $\mathrm{t}=14.3, P=0.002$ ), and a $175 \%$ increase in the incidence of branched spines (t $=140, P<0.0001$ ). Thus, in control animals the number of branched spines represented about $5.1 \%$ of the total number of spines on the distal dendrites of medium spiny neurons in the accumbens, but in animals that a month earlier had their last experience with self-administered cocaine branched spines represented $13.3 \%$ of total spines-a 2.6 -fold increase in the proportion of branched spines on this portion of the dendritic tree.

\section{Anatomy: prefrontal cortex}

In the prefrontal cortex (Cg3) there was a significant effect of treatment on the structure of both apical dendrites (Fig. 2D-F; branches, $\mathrm{F}=5.73, P<0.01$; ring intersections, $\mathrm{F}=5.54, P=0.01$; spines, $\mathrm{F}=114, P<$ 0.0001) and basilar dendrites (Fig. 2G-I; branches, F = 33.7, $P<0.0001$; ring intersections, $\mathrm{F}=141, P<$ 0.0001 ; spines, $\mathrm{F}=29.5, P<0.0001)$. Relative to the control group, animals that self-administered cocaine showed an $11.4 \%$ increase in branches on apical dendrites, no change in ring intersections (although there was a significant decrease in the food group on this measure) and a $20.7 \%$ increase in spine density $(P<$ $0.05)$. For basilar dendrites there was a, $19.7 \%$ increase in branches, a $10.7 \%$ increase in ring intersections and an $11.3 \%$ increase in spine density.

In addition to these changes in dendritic length and spine density we observed unique and seemingly pathological alterations in the shape of the terminal tips of apical dendrites of Cg3 pyramidal cells in rats 


\section{Control}
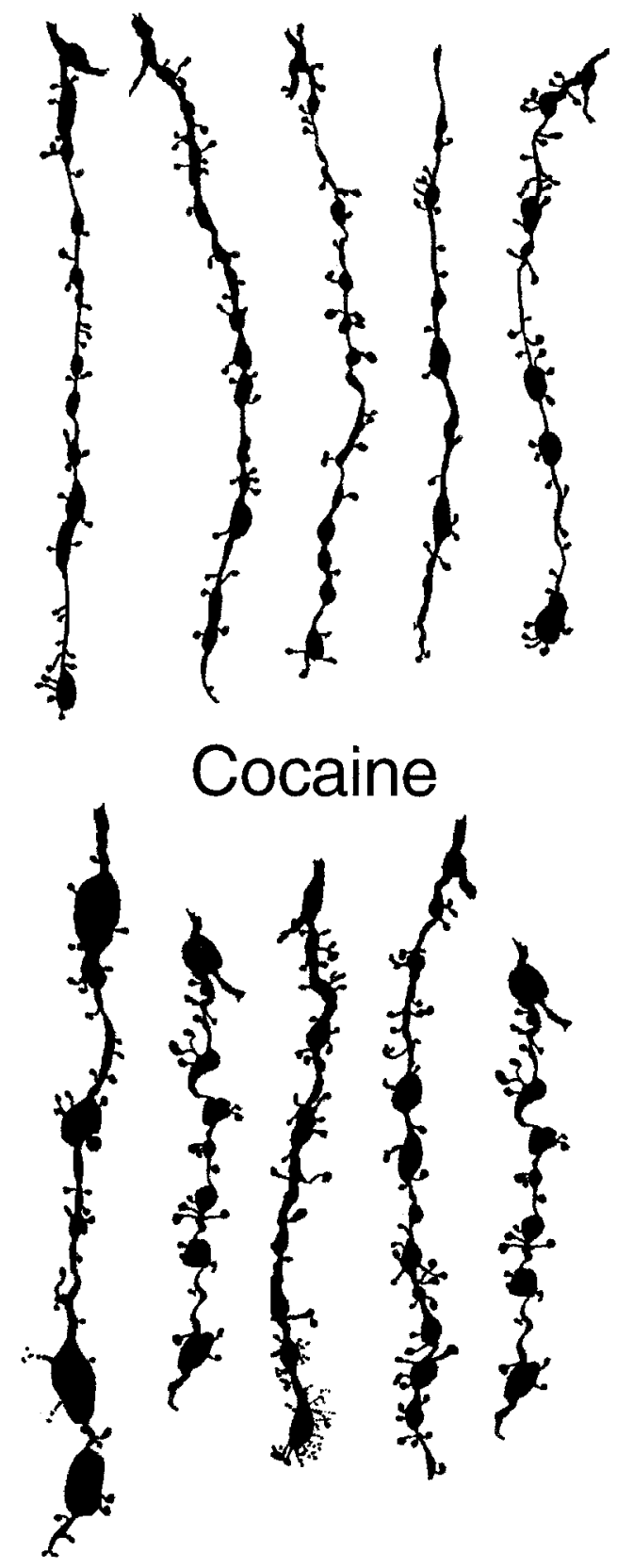

Fig. 4. Camera lucida drawings of examples of bead-like swellings on the terminal tips of apical dendrites on a Cg3 pyramidal cell in a control animal (A) and an animal that had self-administered cocaine (B). Note the large bulbous structures on the dendrites of the animal exposed to cocaine.

that self-administered cocaine. In cocaine animals many of the terminal tips of apical dendrites on $\mathrm{Cg} 3$ pyramidal cells appeared to be misshaped, having a large, bulbous, bead-like appearance (Figs. 4, 5). Beadlike protuberances along the entire length of dendrites are characteristic of double bouquet cells throughout the cortex (Somogyri and Cowey, 1984), but these are not characteristic of neocortical pyramidal cells. In con- trol (and food) animals relatively small bead-like structures on the distal tips of apical dendrites on pyramidal cells in the prefrontal cortex were sometimes seen; an example from a control animal is shown in Figure 4A. However, animals that self-administered cocaine had many more of these bulbous structures and they were visibly larger than in control animals (Fig. 4B, 5). Furthermore, we reexamined tissue from our earlier study involving experimenter-administered cocaine (Robinson and Kolb, 1999a) and did not observe the prominent bulbous structures seen here in rats that selfadministered cocaine. Figure 5 gives three examples of these apparently abnormal apical dendrites from rats that had previously self-administered cocaine. In the top example, it is obvious there is extensive spine growth on the bulbous structures themselves, far beyond that observed in control animals. More typically, there were only a few or no spines visible on the bulbous structures; most spines were evident between the swellings (see the middle and bottom panels in Fig. 5). These apparently anomalous structures were not seen on the basilar dendrites of prefrontal pyramidal cells, nor were they observed on the proximal portions of the apical dendrites in either cocaine-treated or control subjects. Also, these anomalous dendritic structures were not seen in either the parietal or occipital cortex, or on medium spiny neurons in the nucleus accumbens.

\section{Anatomy: parietal and occipital cortex}

Figure 6 shows the results of the analysis of dendrites on Layer III pyramidal cells in the parietal cortex and occipital cortex. In Par1 (Fig. 6A-F) the only significant treatment effects were on spine density for both apical $(\mathrm{F}=20.0, P<0.0001)$ and basilar dendrites $(\mathrm{F}=18.9, P<0.0001)$, and on the number of basilar branches $(\mathrm{F}=12.1, P<0.0003)$. In all cases there was an increase in the cocaine group relative to the control group, and the food group did not differ from control. There was no effect of treatment on any measure of apical dendrites in Oc1 and for basilar dendrites the only significant treatment effect was a decrease in spine density in both the food and cocaine groups (Fig. $6 \mathrm{~L}, \mathrm{~F}=9.95, P<0.001$ ).

\section{DISCUSSION}

Three major findings are reported: 1) In rats with a history of cocaine self-administration experience, last exposed to cocaine 30 days earlier, there was an increase in dendritic arborization and in the density of dendritic spines on medium spiny neurons in the nucleus accumbens and pyramidal cells in the prefrontal cortex. 2) In the nucleus accumbens there was also a large increase in the number of branched spines on the terminal dendrites of medium spiny neurons. 3) In the prefrontal cortex of rats that self-administered cocaine some of the apical dendrites on pyramidal cells ap- 


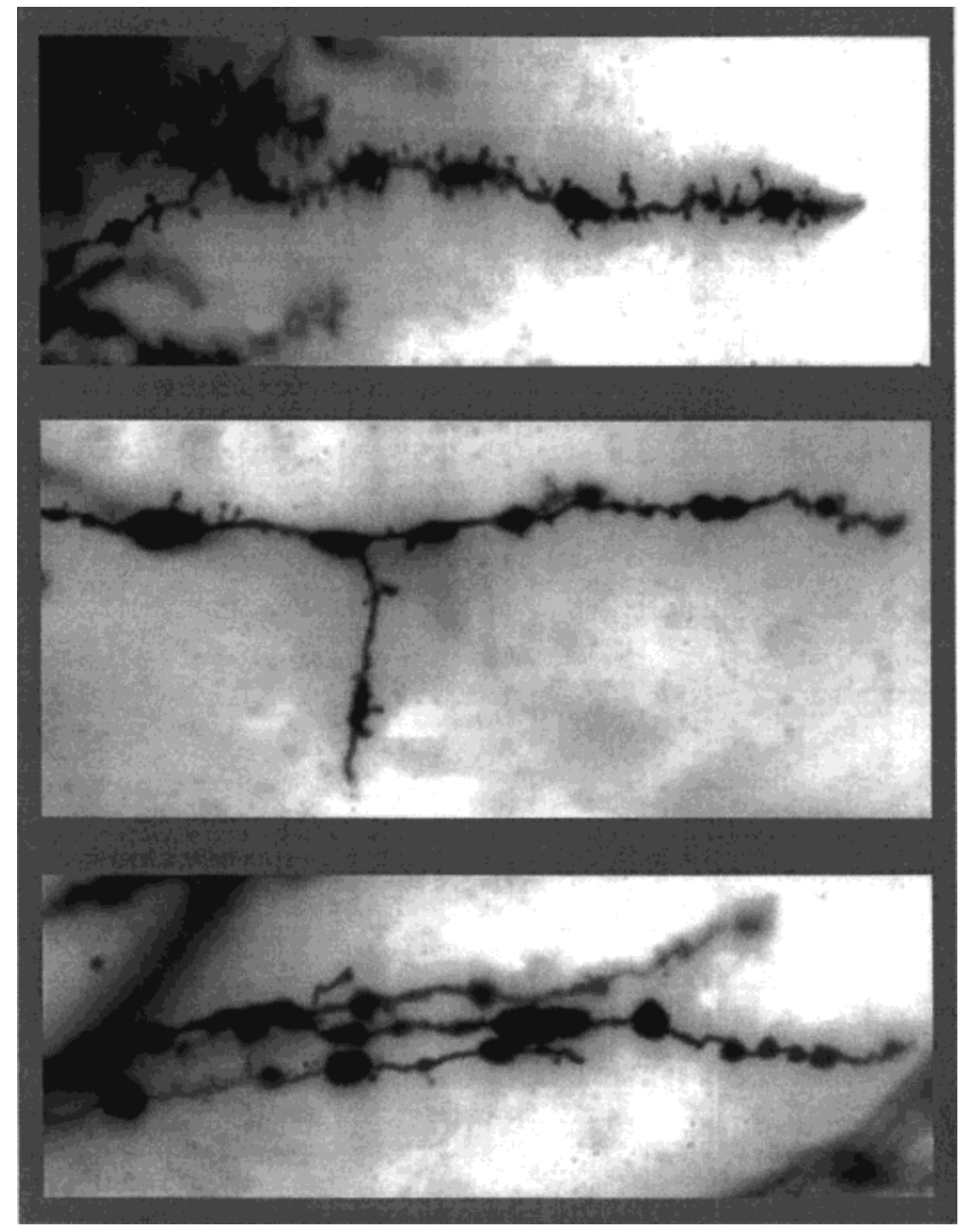

Fig. 5. Photographs of three examples of apparently anomalous apical dendrites on $\mathrm{Cg} 3$ pyramidal cells in rats that self-administered cocaine (see text). peared misshaped, having large, bulbous protuberances.

Most spines on accumbens medium spiny neurons and neocortical pyramidal cells receive an asymmetric (presumably glutamate) synapse onto the head of the spine, and many of these also receive a dopaminergic (symmetric) input nearby, onto the neck of the spine or shaft of the dendrite (Goldman-Rakic et al., 1989; Totterdell and Smith, 1989; Sesack and Pickel, 1990; Smith and Bolam, 1990; Groenewegen et al., 1991; Meredith and Totterdell, 1999). This "triad" arrangement is thought to represent the structural means by which dopamine inputs modulate the excitatory drive on these neurons (Smith and Bolam, 1990; Groenewegen et al., 1991; Goldman-Rakic et al., 1992). Indeed, dendritic spines are considered the major locus of excitatory signaling in the brain. Of special importance here, spines are also thought to be the primary site whereby plastic adaptations alter synaptic activity (Horner, 1993; Harris and Kater, 1994; Rusakov et al.,
1996; Shepherd, 1996; van Rossum and Hanisch, 1999), and changes in the shape of spines, such as the increase in branched spines seen here, may affect synaptic efficacy by modulating either the electrotonic characteristics of the synapse or the local chemical environment (Horner, 1993; Koch and Zador, 1993; Shepherd, 1996). Thus, the changes in dendritic morphology described here, which occur as a function of cocaine self-administration experience, may reflect a reorganization of inputs onto cells in a circuit hypothesized "to serve as the final common path of opiate and psychomotor stimulant reward" (Carlezon and Wise, 1996 , p. 3120), and thus fundamentally alter the interaction between dopamine and glutamate neurotransmission in this circuit.

Of course, we cannot tell from Golgi-stained material how these synaptic inputs are actually rearranged as a function of exposure to cocaine (see Robinson and Kolb, 1997, for a discussion of possibilities); this will require detailed ultrastructural studies. Nevertheless, there is 


\section{Branches}
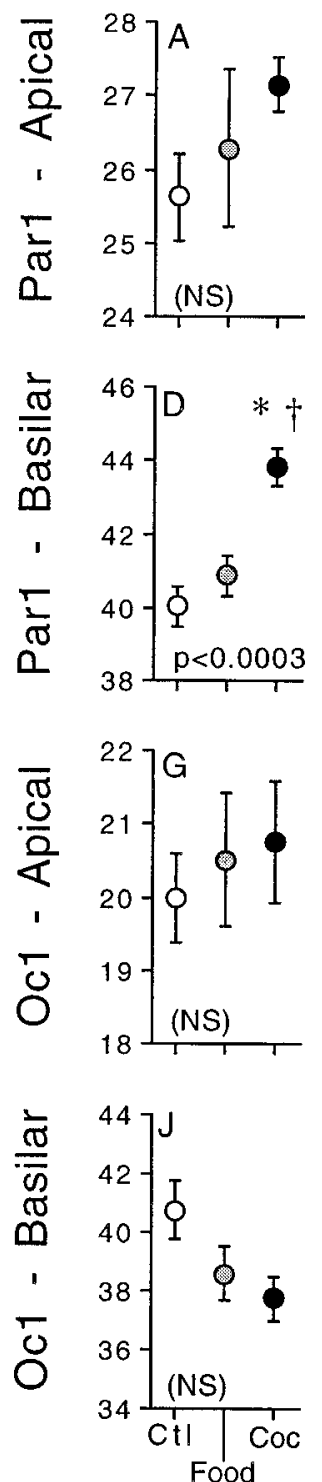

Food
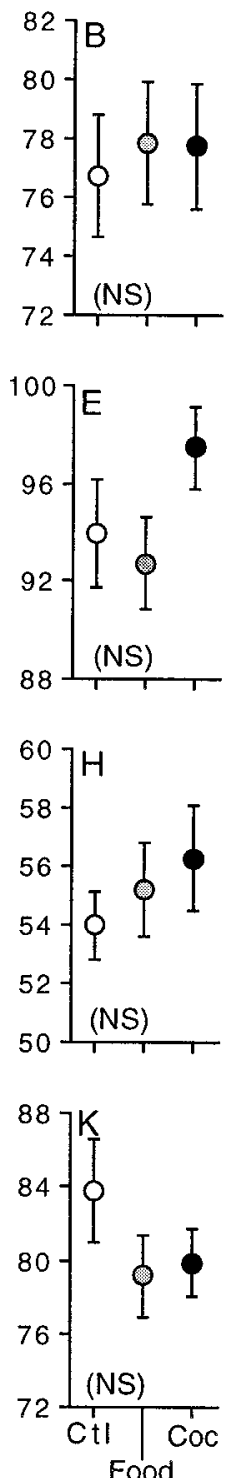

Food
Spines
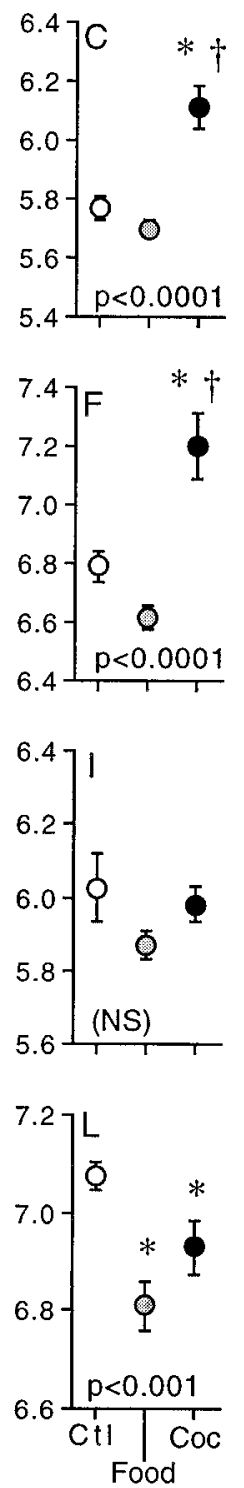

Fig. 6. Effects of food and cocaine self-administration experience on the apical and basilar dendrites of pyramidal cells in the parietal cortex (Par1) and occipital cortex (Oc1). Elements are the same as for Figure 2 (and see text).

considerable evidence from studies of other forms of experience-dependent plasticity that the kinds of changes in dendritic structure described here are indicative of alterations in synaptic connectivity, as assessed by electron microscopy (Greenough et al., 1990; Purves, 1994; Kolb et al., 1998). Indeed, increases in dendritic branching, spine density, and even in the incidence of branched spines has been reported in other structures in association with other forms of experience-dependent plasticity (Geinisman et al., 1989; Trommald et al., 1990, 1996; Comery et al., 1996).

On the surface, many of the effects of self-administered cocaine on dendritic structure reported here seem

very similar to those described previously following experimenter-administered cocaine or amphetamine (Robinson and Kolb, 1997, 1999a) and to those described in the prefrontal cortex of Bonnett monkeys treated repeatedly with deprenyl (Shankaranarayana Rao et al., 1999), which is metabolized to amphetamine and methamphetamine (Feldman et al., 1997). This suggests that cocaine may produce similar long-term neuroadaptations when administered either by an experimenter or by the animal itself. It has been suggested, however, that the neurobiological consequences of psychostimulant drugs can vary as a function of whether drug administration is contingent on an animal's action or not (Smith and Dworkin, 1990; Dworkin et al., 1995a,b). It is possible, therefore, that there are differences in the effects of self-administered and experimenter-administered cocaine on dendritic morphology that are not apparent at the present level of analysis, but would be evident at the ultrastructural level (also see below). This remains to be determined.

As mentioned above, the kinds of alterations in dendritic morphology reported here have been described in other brain regions in association with other forms of experience-dependent plasticity, including long-term potentiation in the hippocampus (Trommald et al., 1990, 1996; Andersen and Soleng, 1998), environmental enrichment (Greenough et al., 1990; Comery et al., 1995, 1996) and learning (Chang and Greenough, 1982; Moser et al., 1994, 1997; Stewart and Rusakov, 1995). Reports of learning-related changes in dendritic morphology are especially relevant to the present experiment, and are one reason why we also studied animals that learned to bar-press for food. It was important to determine whether any changes in dendritic morphology seen in association with cocaine self-administration might be attributable to their learning about the relationship between their action (bar-pressing) and its consequences (cocaine delivery). The animals in both the cocaine and food groups had a similar learning experience, but only the cocaine group showed increased dendritic branching and spine density in the accumbens and prefrontal cortex, which suggests that the changes in dendritic morphology were not merely a consequence of instrumental learning. Also, the effect of cocaine was presumably not due to the development of a motor habit or to the repetitive motor actions associated with bar-pressing because the animals that worked for food experienced these events as well, but did not show similar structural adaptations. Furthermore, the fact that similar adaptations are seen when the drug is given by an experimenter, independent of an animal's actions (Robinson and Kolb, 1999a), supports the contention that they are a specific consequence of exposure to cocaine.

One last point that deserves discussion is our observation of misshaped, bulbous apical dendrites on pyramidal cells in the prefrontal cortex of rats that self- 
administered cocaine. These were not seen in our earlier study using experimenter-administered cocaine (Robinson and Kolb, 1999a) and, therefore, they might represent a unique consequence of cocaine self-administration experience. On the other hand, the difference between the two studies may not be related to whether drug administration was contingent on the animal's behavior, but to the very different pharmacokinetics associated with cocaine self-administered i.v. vs. a single bolus injection given i.p. For example, animals selfadministering cocaine take many infusions that serve to keep plasma drug concentrations relatively constant, whereas an i.p. injection produces a rapid increase in plasma drug concentrations followed by a steady decline. Further studies will be required to resolve this issue.

Nevertheless, the presence of anomalous and apparently malformed dendrites on prefrontal (but not parietal or occipital) pyramidal cells compel the speculation that they represent some sort of neuropathological consequence of self-administering cocaine. If this is true, they might disrupt normal synaptic transmission in this region, impairing frontocortical function. This is an especially interesting notion because there is an accumulating body of evidence suggesting that cocaine addicts show both neurobiological (Volkow et al., 1991, 1992; Biggins et al., 1997; Bolla et al., 1998, for review) and neuropsychological signs of frontal dysfunction (Bolla et al., 1998; Rogers et al., 1999). Neuropsychological signs include impairments in decision-making tasks and in judgment. This raises the possibility that cocaine may induce two very different neuroadaptative processes that contribute to addiction in two very different ways (Jentsch and Taylor, 1999). The structural adaptations in the nucleus accumbens may reflect a reorganization of brain reward systems that render this circuit hypersensitive (Robinson and Berridge, 1993). Indeed, animals with a past history of exposure to psychomotor stimulant drugs are hypersensitive to both their psychomotor activating effects (Robinson and Becker, 1986) and to their incentive motivational effects (Lett, 1989; Piazza et al., 1989; Horger et al., 1990; Shippenberg and Heidbreder, 1995; Mendrek et al., 1998; Deroche et al., 1999), and there is a positive relationship between the ability of drugs to reinstate (prime) drug-taking behavior and their ability to induce psychomotor sensitization (De Vries et al., 1997, 1998, 1999; Vanderschuren et al., 1999). Thus, sensitization-related adaptations in accumbens-related circuitry may render addicts hypersensitive to the incentive motivational effects of drugs and drug-related stimuli via the process of "incentive-sensitization," as described by Robinson and Berridge (1993). At the same time, cocaine may induce neuropathology in the prefrontal cortex, one example of which may be reflected by the dendritic anomalies described here. These could contribute to frontal dysfunction, impair- ing decision-making and judgment (Bolla et al., 1998; Rogers et al., 1999). These two classes of neuroadaptive processes could interact to great detriment in the development of addiction (Jentsch and Taylor, 1999). In the addict, drugs may become "wanted" more and more through the process of incentive-sensitization, because of adaptations in accumbens-related circuitry, while at the same time the ability to make judgments about the future consequences of continued drug-taking becomes more and more impaired, because of dysfunction in frontal circuitry. Together, this combination of motivational and cognitive alterations would be a recipe for addiction.

\section{ACKNOWLEDGMENTS}

We thank R. Gibb for excellent technical assistance. Research supported by grants from the National Institute on Drug Abuse (USA) to TER and from the National Science and Engineering Research Council of Canada to BK.

\section{REFERENCES}

Andersen P, Soleng AF. 1998. Long-term potentiation and spatial training are both associated with the generation of new excitatory synapses. Brain Res Rev 26:353-359.

Bickerdike MJ, Abercrombie ED. 1997. Striatal acetylcholine release correlates with behavioral sensitization in rats withdrawn from chronic amphetamine. J Pharmacol Exp Ther 282:818-826.

Biggins CA, MacKay S, Clark W, Fein G. 1997. Event-related potential evidence for frontal cortex effects of chronic cocaine dependence. Biol Psychiatry 42:472-485.

Bolla KI, Cadet JL, London ED. 1998 The neuropsychiatry of chronic cocaine abuse. J Neuropsychiatry Clin Neurosci 10:280-289.

Browman KE, Badiani A, Robinson TE. 1998. The influence of environment on the induction of sensitization to the psychomotor activating effects of intravenous cocaine in rats is dose-dependent. Psychopharmacology 137:90-98.

Caine SB, Lintz R, Koob GF. 1993. Intravenous drug self-administration techniques in animals. In: Caine SB, Lintz R, Koob GF, editors. Behavioral neuroscience, a practical approach, vol. II. New York: IRL Press at Oxford University Press. p 117-143.

Camp DM, DeJonghe DK, Robinson TE. 1997. Time-dependent effects of repeated amphetamine treatment on norepinephrine in the hypothalamus and hippocampus assessed with in vivo microdialysis. Neuropsychopharmacology 17:130-140.

Carlezon WA, Wise RA. 1996. Rewarding actions of phencyclidine and related drugs in nucleus accumbens shell and frontal cortex. J Neurosci 16:3112-3122.

Chang FL, Greenough WT. 1982. Lateralized effects of monocular training on dendritic branching in adult split-brain rats. Brain Res 232:283-292.

Clark D, Overton PG. 1998. Alterations in excitatory amino acidmediated regulation of midbrain dopaminergic neurones induced by chronic psychostimulant administration and stress: relevance to behavioral sensitization and drug addiction. Addict Biol 3:109-135.

Coleman PD, Riesen AH. 1968. Environmental effects on cortical dendritic fields. I. Rearing in the dark. J Anat 102:363-374.

Comery TA, Shah R, Greenough WT. 1995. Differential rearing alters spine density on medium-sized spiny neurons in the rat corpus striatum: evidence for association of morphological plasticity with early response gene expression. Neurobiol Learn Mem 63:217-219.

Comery TA, Stamoudis CX, Irwin SA, Greenough WT. 1996. Increased density of multiple-head dendritic spines on medium-sized spiny neurons of the striatum in rats reared in a complex environment. Neurobiol Learn Mem 66:93-96.

Crombag HS, Badiani A, Robinson TE. 1996. Signalled versus unsignalled intravenous amphetamine: large differences in the acute psychomotor response and sensitization. Brain Res 722:227-231.

De Vries TJ, Schoffelmeer ANM, Mulder AH, Vanderschuren LJMJ. 1997. Reinstatement of drug-seeking behavior following long-term extinction of cocaine and heroin self-administration: possible role of behavioral sensitization. Soc Neurosci Abstr 23:2147. 
De Vries TJ, Schoffelmeer AN, Binnekade R, Mulder AH, Vanderschuren LJ. 1998. Drug-induced reinstatement of heroin- and cocaine-seeking behaviour following long-term extinction is associated with expression of behavioural sensitization. Eur J Neurosci 10:3565-3571.

De Vries TJ, Schoffelmeer ANM, Binnekade R, Vanderschuren LJMJ. 1999. Dopaminergic mechanisms mediating the incentive to seek cocaine and heroin following long-term withdrawal of IV drug selfadministration. Psychopharmacology 143:254-260

Deroche V, Le Moal M, Piazza PV. 1999. Cocaine self-administration increases the incentive motivational properties of the drug in rats. Eur J Neurosci 11:2731-2736.

Dworkin SI, Co C, Smith JE. 1995a. Rat brain neurotransmitter turnover rates altered during withdrawal from chronic cocaine administration. Brain Res 682:116-126.

Dworkin SI, Mirkis S, Smith JE. 1995b. Response-dependent versus response-independent presentation of cocaine: differences in the lethal effects of the drug. Psychopharmacology 117:262-266.

Edwards G. 1981. Nomenclature and classification of drug- and alcohol-related problems: a WHO memorandum. Bull World Health Organ 59:225-242.

Feldman RS, Meyer JS, Quenzer LF. 1997. Principles of Neuropsychopharmacology. Sunderland, MA: Sinauer.

Geinisman Y, Morrell F, de Toledo-Morrell L. 1989. Perforated synapses on double-headed dendritic spines: a possible structural substrate of synaptic plasticity. Brain Res 480:326-329.

Gibb R, Kolb B. 1998. A method for vibratome sectioning of Golgi-Cox stained whole rat brain. J Neurosci Meth 79:1-4.

Goldman-Rakic PS, Leranth C, Williams MS, Mons N, Geffard M. 1989. Dopamine synaptic complex with pyramidal neurons in primate cerebral cortex. Proc Natl Acad Sci USA 86:9015-9019.

Goldman-Rakic PS, Lidow MS, Smiley JF, Williams MS. 1992. The anatomy of dopamine in monkey and human prefrontal cortex. J Neural Transm 36:163-177.

Greenough WT, Withers GS, Wallace CS. 1990. Morphological changes in the nervous system arising from behavioral experience: what is the evidence that they are involved in learning and memory? In: Greenough WT, Withers GS, Wallace CS, editors. The biology of memory, symposia medica hoechst. New York: FK Schattauder Verlag. p 159-185.

Groenewegen HJ, Berendse HW, Meredith GE, Haber SN, Voorn P, Wolters JG, Lohman AHM. 1991. Functional anatomy of the ventral, limbic system-innervated striatum. In: Groenewegen HJ, Berendse HW, Meredith GE, Haber SN, Voorn P, Wolters JG, Lohman AHM, editors. The mesolimbic dopamine system: from motivation to action. New York: John Wiley \& Sons. p 19-59.

Harris KM, Kater SB. 1994. Dendritic spines: cellular specializations imparting both stability and flexibility to synaptic function. Annu Rev Neurosci 17:341-371.

Horger BA, Shelton K, Schenk S. 1990. Preexposure sensitizes rats to the rewarding effects of cocaine. Pharm Biochem Behav 37:707711.

Horner CH. 1993. Plasticity of the dendritic spine. Prog Neurobiol $41: 281-321$.

Jaffe JH. 1992. Current concepts of addiction. In: Jaffe JH, editor. Addictive states. New York: Raven Press. p 1-21.

Jentsch JD, Taylor JR. 1999. Impulsivity resulting from frontostriatal dysfunction in drug abuse: implications for the control of behavior by reward-related stimuli. Psychopharmacology 146:373-390.

Kalivas PW, Stewart J. 1991. Dopamine transmission in the initiation and expression of drug- and stress-induced sensitization of motor activity. Brain Res Rev 16:223-244

Karler R, Calder LD, Chaudhry IA, Turkanis SA. 1989. Blockade of "reverse tolerance" to cocaine and amphetamine by MK-801. Life Sci 45:599-606.

Katz JL. 1990. Models of relative reinforcing efficacy of drugs and their predictive utility. Behav Pharmacol 1:283-301.

Koch C, Zador A. 1993. The function of dendritic spines: devices subserving biochemical rather than electrical compartmentalization. J Neurosci 13:413-422.

Kolb B, Forgie M, Gibb R, Gorny G, Rowntree S. 1998. Age, experience and the changing brain. Neurosci Biobehav Rev 22:143-159.

Koob GF, Bloom FE. 1988. Cellular and molecular mechanisms of drug dependence. Science 242:715-723.

Lett BT. 1989. Repeated exposures intensify rather than diminish the rewarding effects of amphetamine, morphine, and cocaine. Psychopharmacology 98:357-362.

Mark GP, Hajnal A, Kinney AE, Keys AS. 1999. Self-administration of cocaine increases the release of acetylcholine to a greater extent than response-independent cocaine in the nucleus accumbens of rats. Psychopharmacology 143:47-53.
Markou A, Weiss F, Gold LH, Caine SB, Schulteis G, Koob GK. 1993 Animal models of drug craving. Psychopharmacology 112:163-182. Mendrek A, Blaha CD, Phillips AG. 1998. Pre-exposure of rats to amphetamine sensitizes self-administration of this drug under a progressive ratio schedule. Psychopharmacology 135:416-422.

Meredith GE, Totterdell S. 1999. Microcircuits in the nucleus accumbens' shell and core involved in cognition and reward. Psychobiology 27:165-186.

Moser MB, Trommald M, Andersen P. 1994. An increase in dendritic spine density on hippocampal CA1 pyramidal cells following spatial learning in adult rats suggests the formation of new synapses. Proc Natl Acad Sci USA 91:12673-12675.

Moser MB, Trommald M, Egeland T, Andersen P. 1997. Spatial training in a complex environment and isolation alter the spine distribution differently in rat CA1 pyramidal cells. J Comp Neurol 380 : 373-381.

Nestler EJ, Hope BT, Widnell KL. 1993. Drug addiction: a model for the molecular basis of neural plasticity. Neuron 11:995-1006.

Parsons LH, Justice JB Jr. 1993. Serotonin and dopamine sensitization in the nucleus accumbens, ventral tegmental area, and dorsal raphe nucleus following repeated cocaine administration. J Neurochem 61:1611-1619.

Piazza PV, Deminière JM, Le Moal M, Simon H. 1989. Factors that predict individual vulnerability to amphetamine self- administration. Science 245:1511-1513.

Pierce RC, Kalivas PW 1997. A circuitry model of the expression of behavioral sensitization to amphetamine-like psychostimulants. Brain Res Rev 25:192-216.

Purves D. 1994. Neural activity and the growth of the brain. Cambridge, UK: Cambridge University Press.

Robinson TE, Becker JB. 1986. Enduring changes in brain and behavior produced by chronic amphetamine administration: a review and evaluation of animal models of amphetamine psychosis. Brain Res Rev 11:157-198.

Robinson TE, Berridge KC. 1993. The neural basis of drug craving: an incentive-sensitization theory of addiction. Brain Res Rev 18:247291.

Robinson TE, Kolb B. 1997. Persistent structural modifications in nucleus accumbens and prefrontal cortex neurons produced by previous experience with amphetamine. J Neurosci 17:8491-8497.

Robinson TE, Kolb B. 1999a. Alterations in the morphology of dendrites and dendritic spines in the nucleus accumbens and prefrontal cortex following repeated treatment with amphetamine or cocaine. Eur J Neurosci 11:1598-1604.

Robinson TE, Kolb B. 1999b. Morphine alters the structure of neurons in the nucleus accumbens and neocortex of rats. Synapse 33:160162.

Rogers RD, Everitt BJ, Baldacchino A, Blackshaw AJ, Swainson R, Wynne K, Baker NB, Hunter J, Carthy T, Booker E, London M, Deakin JF, Sahakian BJ, Robbins TW. 1999. Dissociable deficits in the decision-making cognition of chronic amphetamine abusers, opiate abusers, patients with focal damage to prefrontal cortex, and tryptophan-depleted normal volunteers: evidence for monoaminergic mechanisms. Neuropsychopharmacology 20:322-339.

Rusakov DA, Stewart MG, Korogod SM. 1996. Branching of active dendritic spines as a mechanism for controlling synaptic efficacy. Neuroscience 75:315-323.

Schenk S, Partridge B. 1997. Sensitization and tolerance in psychostimulant self-administration. Pharmacol Biochem Behav 57:543550 .

Segal DS, Geyer MA, Schuckit MA. 1981. Stimulant-induced psychosis: an evaluation of animal models. Essays Neurochem Neuropharmacol 5:95-129.

Sesack SR, Pickel VM. 1990. In the rat medial nucleus accumbens, hippocampal and catecholaminergic terminals converge on spiny neurons and are in apposition to each other. Brain Res 527:266279

Shankaranarayana Rao BS, Lakshmana MK, Meti BL, Raju TR. 1999. Chronic (-)deprenyl administration alters dendritic morphology of layer III pyramidal neurons in the prefrontal cortex of adult Bonnett monkeys. Brain Res 821:218-223.

Shepherd GM. 1996. The dendritic spine: a multifunctional integrative unit. J Neurophysiol 75:2197-210.

Shippenberg TS, Heidbreder C. 1995. Sensitization to the conditioned rewarding effects of cocaine: pharmacological and temporal characteristics. J Pharmacol Exp Ther 273:808-815.

Sholl DA. 1981. The organization of the cerebral cortex. London: Methuen.

Smith AD, Bolam JP. 1990. The neural network of the basal ganglia as revealed by the study of synaptic connections of identified neurons. Trends Neurosci 13:259-265. 
Smith JE, Dworkin SI. 1990. Behavioral contingencies determine changes in drug-induced transmitter turnover. Drug Dev Res 20: 337-348.

Somogyri P, Cowey A. 1984. Double bouquet cells. In: Somogyri P, Cowey A, editors. Cerebral cortex, vol. 1. New York: Plenum. p 337-360.

Sorra KE, Fiala JC, Harris KM. 1998. Critical assessment of the involvement of perforations, spinules, and spine branching in hippocampal synapse formation. J Comp Neurol 398:225-240.

Stewart MG, Rusakov DA. 1995. Morphological changes associated with stages of memory formation in the chick following passive avoidance training. Behav Brain Res 66:21-28.

Totterdell S, Smith AD. 1989. Convergence of hippocampal and dopaminergic input onto identified neurons in the nucleus accumbens of the rat. J Chem Neuroanat 2:285-298.

Trommald M, Vaaland JL, Blackstad TW, Andersen P. 1990. Dendritic spine changes in rat dentate granule cells associated with long-term potentiation. In: Trommald M, Vaaland JL, Blackstad TW, Andersen P, editors. Neurotoxicity of excitatory amino acids. New York: Raven Press. p 163-174.

Trommald M, Hulleberg G, Andersen P. 1996. Long-term potentiation is associated with new excitatory spine synapses on rat dentate granule cells. Learn Mem 3:218-228.

van Rossum D, Hanisch UK. 1999. Cytoskeletal dynamics in dendritic spines: direct modulation by glutamate receptors? Trends Neurosci $22: 290-295$.
Vanderschuren LJMJ, Schoffelmeer ANM, Mulder AH, De Vries TJ. 1999. Dopaminergic mechanisms mediating the long-term expression of locomotor sensitization following pre-exposure to morphine or amphetamine. Psychopharmacology 143:244-253.

Volkow ND, Fowler JS, Wolf AP, Hitzemann R, Dewey S, Bendriem B, Alpert R, Hoff A. 1991. Changes in brain glucose metabolism in cocaine dependence and withdrawal. Am J Psychiatry 148: $621-626$.

Volkow ND, Hitzemann R, Wang GJ, Fowler JS, Wolf AP, Dewey SL, Handlesman L. 1992. Long-term frontal brain metabolic changes in cocaine abusers. Synapse 11:184-190.

Weeks JR. 1972. Long-term intravenous infusions. In: Myers RD, editor. Methods in psychobiology. London: Academic Press. p 155168.

White FJ, Kalivas PW. 1998. Neuroadaptations involved in amphetamine and cocaine addiction. Drug Alcohol Depend 51:141153.

Wilson JM, Nobrega JN, Corrigall WA, Coen KM, Shannak K, Kish SJ. 1994. Amygdala dopamine levels are markedly elevated after self- but not passive-administration of cocaine. Brain Res 668:3945.

Wolf ME. 1998. The role of excitatory amino acids in behavioral sensitization to psychomotor stimulants. Prog Neurobiol 54:679720.

Zilles K. 1985. The cortex of the rat. Berlin: Springer-Verlag. 